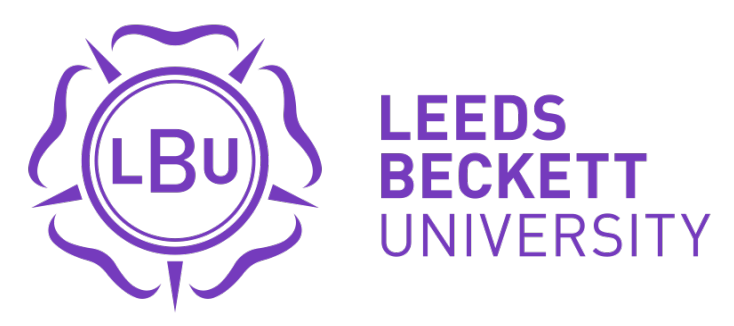

Citation:

Evans, AB and Piggott, D (2016) Shooting for Lithuania: Migration, national identity and men's basketball in the East of England. Sociology of Sport Journal, 33 (1). 26 - 38. ISSN 0741-1235 DOI: https://doi.org/10.1123/ssj.2015-0028

Link to Leeds Beckett Repository record:

https://eprints.leedsbeckett.ac.uk/id/eprint/2572/

Document Version:

Article (Accepted Version)

Accepted author manuscript version reprinted, by permission, from Sociology of Sport Journal, 2016, 33(1): pp26-38, https://doi.org/10.1123/ssj.2015-0028. (C) Human Kinetics, Inc.

The aim of the Leeds Beckett Repository is to provide open access to our research, as required by funder policies and permitted by publishers and copyright law.

The Leeds Beckett repository holds a wide range of publications, each of which has been checked for copyright and the relevant embargo period has been applied by the Research Services team.

We operate on a standard take-down policy. If you are the author or publisher of an output and you would like it removed from the repository, please contact us and we will investigate on a case-by-case basis.

Each thesis in the repository has been cleared where necessary by the author for third party copyright. If you would like a thesis to be removed from the repository or believe there is an issue with copyright, please contact us on openaccess@leedsbeckett.ac.uk and we will investigate on a case-by-case basis. 
Evans is with the Department of Nutrition, Exercise and Sport, University of Copenhagen, Denmark. Piggott is with the School of Sport, Leeds Beckett University, Leeds. UK. Address author correspondence to Adam Evans at abe@nexs.ku.dk.

Lithuanian Acculturation in UK Basketball

http://dx.doi.org/10.1123/ssj.2015-0028

\title{
Shooting for Lithuania: Migration, National Identity and Men's Basketball in the East of England
}

\author{
Adam B. Evans \\ University of Copenhagen \\ David Piggott \\ Leeds Beckett University
}

\begin{abstract}
The accession of the 'A8 states' into the European Union initiated considerable migration into Western Europe. The impact upon local communities has seen significant attention, yet little research exists that focuses upon migrant experiences and identity specifically in sport. This study used a figurational framework to investigate the lived experiences of basketball among male Lithuanian migrants in the rural east of England. Semistructured interviews highlighted participants' motivations to migrate, their acculturation experiences and the role that basketball played during their sojourn. Participants considered basketball a significant means for the expression of national identity and as a focus for their resistance to local racializing processes. Conversely, conflict with established local basketball communities and perceptions of marginalization among migrants were common, creating divisions in local basketball competitions.
\end{abstract}

In May 2004 a group of eight Eastern European states, the 'Accession 8,' (or A8) countries joined the European Union (Gillingham, 2010). This action removed many previous restrictions to international labor laws and initiated a phase of migration from the A8 countries into Western Europe, including half a million migrants into the United Kingdom (UK) between 2004 and 2006 (Blanchflower et al., 2007; Pemberton \& Scullion, 2013). Previous studies have highlighted the complexity of migrant motivations (Cook et al., 2011) and the impact that family ties have upon sojourn length and cause (Ryan et al., 2009). Economic motivations are recognized as key motivational factors behind migration choices (Pemberton \& Scullion, 2013), and structural influences at the state level play a part in contouring such motivations that intersect at the level of agents dependent upon their biography, identity, age, gender, class and ethnicity, as well as perceptions of origin and host culture before migration (Pemberton \& Scullion, 2013). Nevertheless, to date little research exists that highlights the perspectives and the lived experiences migrants in relation to their negotiation of migrant pathways (Cook et al., 2011; McCollum et al., 2012). Instead, the majority of research has focused upon the transstate, diplomatic relationships that enable and constrain this migration pathway (Jileva, 2002), as well as migration direction and intensity (Blanchflower et al., 2007). More widely, the movement of A8 nationals to the UK has seen significant media and government attention, often framed in terms of moral panics and dire economic forecasts relating to service provision in education, healthcare and sport, among other fields (Green et al., 2007; Pemberton, 2008; Pemberton \& Scullion, 2013).

In the rural east of England in particular, the influx of migrants from Poland, Latvia and Lithuania has seen significant focus, including the commissioning of a full report by one local authority (Kenny \& Bedford, 2012). In such contexts, sport can play a key role in shaping intercultural transfer among migrant groups (Burdsey, 2004, 2006b, 2009; Evans, 2014; Fletcher, 2012), creating multilayered identities that can be reproduced or challenged through sporting affiliation, consumption and participation at both the global and local level (Burdsey, 2006b). The present study therefore aimed to highlight how sporting affiliation and national identity impacted upon the lived experiences of a group of Lithuanian migrants in the rural East of England in relation to basketball participation.

Basketball holds significant cultural importance to Lithuanians as a national sport (Kaunaite, 2012; Selvaraju et al., 2012), and between 2008 and 2014 the number of basketball teams in Lincolnshire (a rural county in the East of England) doubled in number, predominantly due to the founding of new Lithuanian teams. Despite this growth, however, the transition for Lithuanian migrants into existing British basketball structures has been problematic, and local resistance to Lithuanian teams has resulted in several altercations, protests from local and Lithuanian teams, and even cases of assault between players. Consequently, in a similar action to that which has seen numerous 'all Asian' association football leagues set up across the UK (Burdsey, 2004; McGuire et al., 2001), Lithuanian players set up a rival, separate league competition to the existing league structure in Lincolnshire in 2012. Such actions are suggestive of perceptions of cultural mutual exclusion from both migrant and host population that goes beyond sporting practice. These factors are encapsulated in previous studies of migration as a global phenomenon, within which the key debates are outlined in brief below.

\section{Migration as a Global Phenomenon}

The migration of people around the world is often framed by conceptualizations of globalization processes (Maguire, 2002) associated with increased transfers of commodities, people and ideology around the globe. The increased scope and intensity of such global 'flows' has eroded the regulatory power of the interstate system (Dicken, 2007; Maguire, 2002), although this erosion should not be overstated. As Giulianotti and Robertson (2007) outline, an overemphasis on the limitless nature of global 'flows' can be problematic, and migration research now emphasizes the spatiality, temporality and enabling and constraining geographical, economic, geopolitical and cultural factors associated with flows of people at both the global and local levels (Bude $\&$ Dürrschmidt, 2010; Giulianotti \& Robertson, 2007; Massey, 2005). In short, it has become widely accepted that the global and the local exist alongside one another as groups adapt to and resist globalizing tendencies (Bairner \& Barbour, 2005; Evans, 2014). Indeed, Giulianotti and Robertson (2007) have outlined how this interplay between global and local forces in specific contexts can be encapsulated in the concept of glocalization (Giulianotti \& Robertson, 2007). Similarly, the concept of acculturation has be used 
to describe how individual experience is contoured and negotiated as migrants traverse spatial contexts (Weedon, 2012). The concept of acculturation refers to the complex multidimensional process of learning that occurs during continuous contact in a manner in which identities are developed and changed. A number of acculturation strategies have been noted which emphasize the impact of space, place and temporality on migrant experiences, including; i) assimilation, or full integration with a host culture, ii) separation, in which a migrant group does not engage with a host culture, iii) marginalization, in which neither interaction with a host culture nor maintenance of a migrant culture is desired, and iv) integration, in which both host and migrant cultures are maintained (Berry, 2005). Instead, individual or groups of migrants interact with host communities based upon experiences of cultural practices such as language, food, media, traditions (Harrolle \& Trail, 2007) and sporting affiliation and participation (Ha, 2012; Harrolle \& Trail, 2007; Hosper et al., 2008).

Moreover, acculturation is not always a free choice for migrants and although many often create their own links between spaces, either formally or informally, migrants must also adapt to the complex political economy in which they are situated (Weedon, 2012). Similarly, although migration has been viewed as a symptom of global interconnectedness, the embodied nature of migrants also sets limits on the extent and velocity of their global movements. For example, even the movements of the hyper-mobile are limited by their access to modes of travel, international law, and their own life span (Bude \& Dürrschmidt, 2010; Evans \& Stead, 2014). Migration, as a global flow, is therefore subject to limits, to push and pull factors, to geographical, geopolitical and economic boundaries, as well as influenced by migrants' embodied capabilities, their ability to 'sell' their skills, and their access to the means to migrate (Carter, 2011a; Maguire, 2011). Indeed, the ability of some to migrate by necessity renders others immobile. Furthermore, the intersections of ideologies centered upon spaces of origin and host spaces also play a part in shaping migration. Shared memories of an inherited past among migrants can create 'imagined communities' that go beyond the bounds of face to face interactions grounded in idealized images of spatial 'origins' which can be both unifying and used to resist assimilation with a host culture (Burdsey, 2006b), because they are perceived to be sovereign and have limits (Anderson, 2006). Such processes illustrate how socially produced 'we' and 'they' groups can produce and generate national and ethnic Diaspora. These form an interpretive frame referencing economic, political and cultural dimensions relating to socially constructed groups of migrants in space with a symbolic link to past traditions across historical and geographical boundaries (Anderson, 2006; Brah, 1996; Fletcher, 2012). Consequently, Diaspora exist locally, but imagine themselves globally (Anthias, 1998; Bairner, 2012; Hoelscher \& Alderman, 2004). Moreover, traditions and culture from host and origin intersect at the level of the individual both transnationally, and also transethnically in a fluid manner which can continuously reinforce, transform or fragment migrant identities (Anthias, 1998; Burdsey, 2006b; Hall, 1990). Indeed, identification with sporting values can change over time as migrant sojourns become migrant settlements (Adair \& Rowe, 2010; Burdsey, 2004, 2006b, 2009).

The impact of sporting acculturation strategies can be varied. For example, when sport is used by some migrant groups to resist cultural assimilation, discourses focusing upon 'threat' and 'fear' can be produced among host communities (Burdsey, 2006b). Consequently the 'racialization of space' can occur as relative population densities are turned into absolute markers of racial division in space along with the construction of discourses of threat, exclusion and 'no go areas' within which relative population densities are changed into absolute markers of 'racial,' ethnic or national division (Cohen, 2008). When articulated through images of confrontation and moral panics focusing upon 'invasions' and the like (Burdsey, 2006b), social exclusion can occur and in some cases this gives rise to ideas of a monocultural history in which a fusion of national and racial ideologies can ideologically exclude communities from sporting cultures (Cohen, 2008). Several studies have outlined how such groups can be faced with sociocultural marginalization from sporting competitions, careers and positions in sports governance (Adair \& Rowe, 2010), particularly in relation to the British Asian Diaspora (Burdsey, 2004, 2006b; Lusted, 2009) and those of Afro-Caribbean descent (Burdsey, 2009). For groups such as British Asians and migrants from beyond Europe, socially produced and contested notions of race and ethnicity often have a phenotypical or biological dimension that can nevertheless can be called into question. For example, 'white' groups of migrants in the Western European context have frequently been subject to cultural 'racialization processes' leading to their marginalization (Fox et al., 2012). Racialization is invoked when 'racial' categories enter discursive and institutional practices in a manner which contours social relations (Fox et al., 2012; Garner, 2006). Clearly, rather than being based upon only 'visible' markers of 'race,' the processes behind the production, reproduction and resistance of 'racial' or ethnic categories are grounded in power relationships that change over time, and that reflect more general sets of geopolitical, economic and cultural interdependencies at both the global and local level (Dunning, 1999; Fox et al., 2012). Consequently, 'racialization' does not require phenotypical or biological difference, but can also make use of sociocultural and economic differences. For example, it has been highlighted how 'whiteness' is often assumed to command the center due to processes of normalization, as opposed to more peripheral 'race' categories, including 'blackness,' which is often othered in host communities in the West (Long \& Hylton, 2002; Long et al., 2014). Consequently, it has been assumed that 'Other White' migrant groups have fewer problems, in adapting to a new context. At the same time, however, it is important to recognize that such groups of migrants, although ostensibly less visible in their ethnic otherness, are nevertheless diverse and subject to other divisions that go beyond the visible markers of 'race' (Demireva, 2011). Simply, not all the 'wages of whiteness' (Roediger, 1999) can be invoked by all 'white' migrant groups; differences in language, class and geopolitical or legal status can still exist. In short, 'whiteness,' nor any other phenotypical difference normally associate with 'race,' is no monolith. Instead, like other 'racial/ethnic' categories, 'whiteness' as an ideological construct represents a heterogeneous multiplicity of national, regional and ethnic identities which are shaped by broader geospatial relationships and power dynamics that change over time, and which intersect with other markers of difference (including gender, age and (dis)ability). Whiteness, therefore, is a process (Long et al., 2014; Satzewich, 2000).

For example, although the free-market policies of New Labor in the UK quickly meant that nearly 1.5 million Eastern Europeans entered the country seeking work, the majority moved into the low-end sector of the economy (Fox et al., 2012). This led to the Home Office taking a 'managed migration' policy in 2002, where workers were allowed in in key sectors. The implicit connotation of this policy is that specific groups, particularly EU migrants, were more racially desirable than others. One consequence of this was that the unexpectedly large numbers of A8 migrants entering the UK meant specific groups, such as Romanians, to be symbolically denuded of their 'whiteness' in such sources as the tabloid media which emphasized the negative aspects of their immigration, including their high numbers and negative stereotypes, such as linking them to crime (Fox et al., 2012). Other groups, however, are often subsumed into wider 'East European' categories, which are in turn often subsumed within generic categories of European Whiteness - and are therefore less visible in such negative discourses (Long \& Hylton, 2002; Long et al., 2014). As will be observed below, our group of Lithuanian migrants had been negatively stigmatized at the local level, both in terms of their 
wider relationships with local populations, and within sport. A figurational theoretical framework was adopted to help us investigate their experiences of migration to the UK, and it is to this approach that the discussion now turns.

\section{The Figurational Approach}

Centered upon the work of Norbert Elias, the figurational perspective is established in studies that outline trends in sports globalization (Maguire, 2002, 2011), national identity and sport (Maguire, 2011) and sports migration networks (Evans, 2014). Elias was concerned with challenging false dichotomies in sociological thought, including individual-society, internal-external and object-subject (Elias \& Schröter, 1991). For example, Elias argued that individual, 'I' identities both constitute and are contained within complex webs of social relationships that in turn produce and reproduce 'we' or 'they' identities (Jarvie \& Maguire, 1994). These webs of relationships exist in contested, tensile, dynamic power balances, or figurations in which the short-term intended actions of all individuals interact to create long-term unintended consequences. Figurations are continually in flux (Elias et al., 2000; Elias \& Schröter, 1991; Elias \& Scotson, 1994), due to the interdependent, multifaceted, diffuse and contested nature of power within them. Social relationships can be both enabling and constraining. Those with greater power, or 'established groups,' have a larger capacity to influence and constrain the actions of others in a figuration, or 'outsider' groups, and yet outsider groups can also resist, transform and change their own social conditions.

Just as individuals and societies are interdependent, then, as are established and outsider groups (Elias \& Scotson, 1994). Elias and Scotson (1994) outline four established-outsider relationships that relate to interclass and interethnic/ 'racial' relationships, including 1) the tendency for members of established groups to perceive outsiders as 'law-breakers' and 'status violators'-that is, anomic, 2) the tendency for established groups to judge outsiders in terms of the 'minority of the worst,' or in some rare cases (such as in the myth of black athleticism), the 'minority of the best' if it serves to reinforce a collective myth about an ethnic group, 3) the tendency for outsider groups to accept the established group's stigmatization of them (or to internalize the 'group charisma of the dominant group and their own 'group disgrace'), and 4) the tendency for established groups to view outsiders as in some way 'unclean.' Established groups also tend to create collective fantasies about outsider groups, often with genetic connotations that exculpate the established group from any blame. 'Race' and 'ethnic' terms serve the same purpose by singling out for attention something that is peripheral to power relationships by focusing upon skin color, or cultural differences (Dunning 1999: 189-90).

Figurations operate at both the global and local level (Maguire, 2002). Processes such as globalization have lengthened interdependency chains so that migrant experiences can be influenced by people migrants may never meet, including governments, service providers, lawyers in the field of labor-law, sports governing bodies and the media (Maguire, 2011). Culture is, however, contested within figurations because individuals or groups can resist, reinterpret and reproduce cultural ideologies. This cultural contestation, particularly in sport, is temporally and spatially sphere-bound within glocal spaces which are interdependent across space and time through and embodied migrant experiences (Evans \& Stead, 2014; Klein, 1994). Glocal sporting cultures can become accepted in specific spaces as 'normal' (Massey, 2005), and state institutions, as key, ostensibly 'legitimate' components in the facilitation of the lengthening of interdependency chains and the production of decreasing contrasts and increasing varieties in behavior and identity within specific geospatial contexts, are central elements in this process (Elias et al., 2000; Elias \& Jephcott, 1983). The internalization of the norms and behaviors associated with specific sports cultures can exist beneath the level of conscious control, so that they appear to be rational and grounded in local ideologies of acceptability. Behaviors which transgress these norms become taboo, or above the threshold of repugnance toward socially accepted conduct (Elias \& Dunning, 1986). These levels of social acceptability are formed in the nondiscursive aspects of culture that bind people into groups, including unspoken habits and patterns of behavior internalized as the habitus (Elias, 1982; Elias \& Schröter, 1991). The habitus represents the manner in which experiences become familiar, including the mundane actions of everyday life, so that socially learned acceptable behaviors meld with the emotions to produce the 'durable and generalized dispositions' that become a person's 'second nature' (Elias, 1978; Maguire, 1991, 1993). Habitus therefore relates both to identity, to one's knowledge of self, and to personal choices and actions. At the same time it is transferable and enduring and does not mechanically constrict the actions of individuals. It can be changed, resisted and contested. Habitus therefore exists at the fulcrum, or 'hinge' between sociogenetic and psychogenetic processes, and helps to conceptualize how individual actions are influenced by social practices at the same time as individual actions can influence social practices (Elias \& Dunning, 1986; Jarvie \& Maguire, 1994; Thing, 2001).

Because experiences are also embodied, habitus development has a spatial element (Bude \& Dürrschmidt, 2010; Evans \& Stead, 2014). Cultures, particularly those related to ethnic identities, exist in space (Lechner \& Boli, 2008) and global flows of migration clearly influence the exchange of ideas and practices without homogenizing them. Cultural habitus' are resisted, reinterpreted and changed through the acculturation strategies of migrant groups over time and space (Maguire, 2002). For migrants, spaces exist simultaneously so that acculturation can be viewed as a continuous process through which embodied individuals negotiate the cultures of host and origin. This helps to account for the 'resistant and adaptive potentialities of the migrant in transition as well as the potentially homogenizing tendencies of the host culture' (Carter, 2011b; Weedon, 2012). Sporting cultures are also subject to such processes, and it is a study of one such interchange experienced by Lithuanian migrants in the UK that forms the subject of this paper.

\section{Study Methods}

The study used semistructured interviews which investigated the lived experiences of male Lithuanian migrants in the East of England. Second only to London and the South East, the East of England has been one of the main destinations for migrants from Lithuania since the turn of the millennium, and over 200,000 Lithuanians have moved into the area between 2001 and 2011 (ONS, 2012). As a predominantly rural region, such an influx of migrants has had a significant impact upon local perceptions of migration, none more so than in regional basketball competitions, within which, primarily due to Lithuanian migrants, participation levels have more than doubled since 2008.

To recruit participants, the second author drew upon his personal networks as a long-term member of the local basketball league. In addition to playing for 15 years, he had also been on the league committee and coached the country representative team, including a number of Lithuanian players. He was therefore well placed to identify and approach Lithuanian migrants who: a) had a good understanding of spoken English; b) were influential members of the basketball community (i.e., they had coaching, refereeing or management roles); and c) represented the range of the six Lithuanian teams in the county. Given the importance of 
English language skills in recruitment, the sample perhaps overrepresented long-term migrants (average of 7.6 years in the UK) and those with university education (two thirds of the sample). This bias was also reflected in the fact that the participants had often taken coaching or managing roles with their respective teams. In total, however, nine male members of the Lithuanian basketball-playing community participated in the study (see Table 1).

\section{[ID]TBL1[/ID]}

Participants were interviewed around their normal basketball practices and after games in sports centers and schools, often in cafes or meeting rooms. Interviews therefore had to be tailored to fit into shorter time periods and were often limited by the participants' relative command of English, which varied considerably, made some interviews challenging and excluded some potential participants from the study. It must also be recognized that, for some participants, answers offered in English could potentially have been less illustrative or expansive than might have obtained from an interview conducted in Lithuanian. As a result of these factors, interviews lasted between 15 and $42 \mathrm{~min}$ (average $28.2 \mathrm{~min}$ ).

Questioning focused upon several key areas, including participants' acculturation experiences, the meanings they attached to basketball contextually and experientially, and their feelings in relating to their position of members of a Lithuanian Diaspora in the UK. We also discussed participants' narratives of migration from before their arrival to the UK, thereby avoiding the 'retreat to the present,' and attempted to contribute as 'dispassionately' as possible by adopting a dialectical approach between method and theory to understand the data (Dunning, 1999).

The interview data were audio recorded and transcribed verbatim. The resultant interview transcripts were coded into categories according to interview questions, which were, in turn, generated through sensitivity to figurational concepts and the substantive literature in the field. Effort was made to minimize the imposition of meanings, categories, concepts and terminology upon data during early analysis (Allen-Collinson, 2009) by adopting a dialectical approach between data and our figurational standpoint. Themes were refined via constant comparison between data and figurational concepts (Bryman \& Teevan, 2004) to enable the situation of individual experiences within the wider webs of power in which they might have occurred. The authors consequently sought a 'two-way traffic between two layers of knowledge: that of general ideas, theories or models and that of observations and perceptions of specific events' (Elias et al, 1987: 20[AUQ1]) in seeking to produce an analysis with reality congruence (Dunning, 1999), or ideas that more adequately reflected participants 'reality' rather than absolute 'truth' (Murphy et al., 2000; Van Krieken, 1998).

The figurational approach argues that it is not possible for the researcher to be entirely objective during research. Rather, as Baur and Ernst (2011) have argued in their thesis on managing subjectivity and the recognition of potential insider perspectives (or verstehen) and subjectivity (or perspektivität) are prerequisites for grasping meaning. In short, we were conscious of seeking a balance between involvement and detachment with study participants and their experiences (Dunning, 2005). Sufficient involvement was necessary to establish contact and rapport (even empathy), tempered by a degree of detachment necessary for sociological theoretical reflection on how their experiences could be understood in light of theory. The composition of the research team, within which the first author was an outsider and the second author was an 'insider' to the local basketball figuration, facilitated a balance between involvement and detachment that was maintained through the study, and carried over into data analysis. For example, before research, we were able to design our study aims based upon discussions where the first author took a primarily theory-driven perspective that formed a counterpoint to the second author's experiences (the insider to the figuration) of ongoing events within the local basketball fraternity. In addition, during analysis both authors independently coded interview data before engaging in a dialectical and reflexive process of comparison and reflection through which codes were refined in a reflexive manner to delineate (and minimize) the potentially misguiding impact of our own parteilichkeit (Baur \& Ernst, 2011). The following section highlights key themes which emerged from this analysis.

\section{Results and Discussion}

Several trends emerged in the data which related to three overarching themes in descriptions of participant experiences. These themes cohered around facilitating and limiting factors to acculturation during migration, the centrality of basketball in migrant identities and to migrant interactions with the local community through basketball. We present data relating to each of these themes below.

\section{“We Didn't Know Anybody. We Needed Actually Help When We Came Here..." Lithuanian Experiences of Migration}

The decision to migrate was framed by participants in terms of the interdependence of the spaces of host and origin. Participants recalled their quality of life in Lithuania in a negative light, particularly in relation to their financial status in the UK, which was considered to offer the potential to achieve higher wages, some of which could be returned home to family members at a favorable exchange rate. Consequently, as in a number of other cases of migration in the European Union (King, 2002), financial motivations to migrate over both the short and long-term were a key consideration. For example: 
"To get some money for one day, if I was working in my country in the field it was very small money and when I come here I can feel like a man, like people, you know. A better life." (Jonas)

Nevertheless, higher wages did not always equate with feelings of wellbeing, and perceptions of alterity, isolation and in some cases confusion were commonplace among participants. Lukas described these feelings:

"[You] don't know anybody, nothing, you know, first couple of weeks it was... very strange. Everything is different you know: cars driving on other side; if you go to shower you've got hot and cold water; you use your phone, put it on charge and it's three pins. It's everything strange." (Lukas)

These feelings were often grounded in negative experiences encountered in the workplace during the initial phases of their sojourn. Participants described numerous instances where they or their friends had been exploited by unscrupulous agents, which combined with language difficulties and an absence of personal networks such as friends and family to create acute feelings of dislocation. It is largely assumed that in such contexts 'Other White' groups have fewer adaptations problems because of their 'invisibility' in some European countries, but at the same time it is important to recognize that this group is diverse, and language barriers can also produce division (Demireva, 2011). Furthermore, in contrast to trends observed among other groups of migrants (Burdsey, 2006b; Evans \& Stead, 2014), participants often traveled alone or in small groups and felt isolated from compatriots:

"We didn't know anybody. We needed actually help when we came here but you see some Lithuanians - not very good people you know - they didn't help you, they just want to take money from you." (Dominykas)

Together, these factors are indicative that the group of Lithuanian migrants encountered in this study shared many of the characteristics of an 'outsider' group (Elias \& Scotson, 1994), with low levels of association with others, even compatriots. Moreover, our participants also highlighted the unplanned nature of their migration, and reference was made to the UK in only a generic, ideological manner (often focusing upon relative wealth in comparison with 'home') that was not always concomitant with reality. Geographical specificity was lacking and many participants had moved the UK without the guarantee of work, or without even knowing which part of the country they would move to:

"We first came to Bognor Regis, just for one week with my wife. Then we meet some people in Norfolk. We don't know where we were going actually, just North of England, okay, five or six hours or whatever, then after a couple of weeks we came here and stayed here" (Dominykas)

Despite these problems, however, and despite consistently finding themselves part of a marginalized outsider group (Berry, 2005; Elias \& Scotson, 1994) with minimal contact and interaction with local indigenous groups, many study participants had enjoyed the lifestyle and standard of living in the UK, and had turned their sojourn into a more permanent stay without making a conscious resolution to do so:

"I thought we'll earn some money and get back to Lithuania, so that's how we ended up here, but we're not coming back. We might do, but we just got into the lifestyle here and kind of got stuck." (Nojus)

This was a common position among participants, who had mainly planned to move to the UK for a short period to make money before returning to Lithuania. Following Eade and Garbin's (2007) research with Polish labor migrants in London, many participants started out as 'hamsters' (a one-off move to build capital and return), but quickly turned into 'stayers' (who intend to remain for the foreseeable future), though most envisaged a potential return to Lithuania in the future if economic conditions improved there (Eade \& Garbin, 2007).

Nevertheless, despite many participants' lengthy stay in the UK, their sense of being away from 'home' also focused upon sport, particularly basketball, which both they and their compatriots had continued to play in the UK. Indeed, for many of them, basketball competitions were their principal means of contact with the indigenous community (Berry, 2005) and as an 'escape' from their working experiences and, in some cases, family troubles:

"I got little problems just now with my wife, divorces and that, you know... and basketball I just kind of relax when I go after job. I don't think about other things, what's going on at home, you know...Basketball is help...all people like one big family... all friends I find here, it's from basketball" (Lukas).

As a relatively recent migrant (three years), and perhaps because of his confidence in spoken English, Lukas actively sought out opportunities to play and built stronger bonds of association with both compatriots and members of the established local group based around basketball. Nevertheless, his case was exceptional. Many other participants did not play at all for the first few years of their stay, mainly due to a lack of basketball infrastructure locally and a lack of knowledge of opportunities. Consequently, they often started playing "in the streets" (Emilis) and joined teams only by luck, through meeting the 'right' people within the established basketball community more locally. Dovydas explained his experiences:

"We start playing outside, just for our passion. And after that, a couple of guys explain that they have competitions, who want to know what we're doing. And we sit down, three guys, and we decide; why not create a new team, Lithuanians?" (Dovydas) Basketball seemed to offer an opportunity to relax, to get away from work and to overcome participants' initial isolation through the formation of stronger bonds of association with other Lithuanian basketball players. It is to a discussion of the social significance of basketball during participants' stay in the UK that the discussion now moves.

\section{"More than a Religion!" Basketball and Lithuanian National Identity}

Basketball has been described as a 'national' sport in Lithuania (Kaunaite, 2012; Selvaraju et al., 2012), a claim that is supported by the high levels of public funding it receives in Lithuania compared with other sports (Cingiene \& Laskiene, 2004). Moreover, basketball continues to represent a site of (masculine) sporting prowess in which Lithuanian identity-and success - has been framed in terms which emphasize how this relatively small country can compete with, and often beat, its 
larger neighbors. The recent history of Lithuania, including absorption into the Soviet Union in 1945 with its prevailingly Russian cultural practices until independence in 1991, has led to a struggle among Lithuania and the other Baltic states for a sense of identity and of recreating their own national histories in which sport plays a key role (Taagepera, 2009). In short, basketball has long been a conduit through which Lithuanian 'outsiders' could celebrate their achievements in the face of competition (and oppression) by 'established' geopolitical groups, such as the Russians.

Indeed, basketball acted as a focus through which participants' cultural and national identities were expressed, often in opposition to local sporting cultures which, as will be observed, served to racialize them. Participants identified with national success in basketball, viewing it as an expression of 'their' Lithuanian national identity. Familiarity with basketball spaces, practices and past events were associated with stronger bonds of association between their imagined community. In particular, international victories demonstrated emancipation from a history of Soviet domination. One participant even gave us a copy of the film "The Other Dream Team"-focusing on the Lithuanian team's emotional victory over the Russian team in the 1992 Barcelona Olympics - to help us understand the centrality of the sport in the formation of post-Soviet national identity. These stories and images, synonymous with a national 'we' group, were highly familiar and rehearsed by almost all our participants and appeared to help them connect them with a uniquely Lithuanian imagined community (Anderson, 2006) that was "small but determined" (Lukas). Such identification with national achievements became particularly acute in the face of the cultural isolation participants felt as part of an outsider group (Topič \& Coakley, 2010) following migration to Britain.

Basketball was therefore central to the production and reproduction of this shared identity in both the present and in a shared, imagined past, and was described successively as 'a religion' (Armandas), 'a national obsession' (Jokubas), and as a method for resisting domination by other, larger they-groups. For example, the small population of Lithuania -"We are just three million!" (Justas, our emphasis) — was repeatedly used to underline the magnitude of Lithuanian success against the odds in basketball. Moreover, Nojus outlined how he considered basketball success to be a way in which Lithuanians could challenge their previous marginalization, or outsider status, in Lithuania itself:

"... .because we were occupied by [USSR] for a really long time, and it was getting our independence back, with them playing basketball, and we were better." (Nojus)

Furthermore, participants described how basketball represented a personal expression of their Lithuanian heritage. The opportunity to both practice 'Lithuanian' cultural norms through basketball, and the embodied act of playing, were considered vehicles through which to connect with an imagined past within which resistance against larger they-groups was integral. Participants expressed this 'we' identity through wearing specific 'Lithuanian' clothing and motifs, speaking only in Lithuanian and engaging in Gemeinschaften activities around games were symbolic of Lithuanian habits and culture (Elias \& Dunning, 1986). Dominykas summarized how he felt that basketball had become an expression of his national identity:

"All my team knows that I'm shooting; I'm going to shoot for people in Lithuania and I'm shouting in Lithuanian language... I always put on a Lithuania t-shirt and when you're playing basketball you will never forget you're Lithuanian, never, ever... it's more than a religion... basketball is what we're proud of; this is what we can show to Europe, the world, that we're three million people and we can play very well.” (Dominykas)

Study participants therefore assumed 'their' national success and basketball culture were part of their own, personal sporting experience, frequently associating their own expertise with the preeminence of basketball in Lithuania (Cingiene \& Laskiene, 2004). Moreover, participants frequently considered their possession of knowledge and skills to be of greater value than local British practices. Such perceptions were grounded in the limited British success in basketball on the world stage. Participants were also cognizant of the lack of sociocultural preeminence in British culture when compared with the Lithuanian context. This Lithuanian basketball habitus lent itself to perceptions of superiority over indigenous participants, both as players and in terms of 'knowing' how the sport should be played:

"I think Lithuania playing very well basket you know, and Englishmen are learning a bit you know... [but] the English was not better than us. They're trying to be better, they're trying. It's difficult" (Jokubas)

Elias and Scotson (1994) outline how established groups can stigmatize outsider groups by judging them against the 'minority of the worst.' In this case, our participants associated British players with a generally low level of ability. For participants, this represented a role-reversal of their position within wider British society, in which they felt marginalized. This introduced a sociospatial element specifically to basketball. Participants described how, through their presence and by enacting 'their' basketball culture, basketball spaces within Britain could become temporarily 'Lithuanian:'

"When we go to [local competitions] there are all Lithuanian guys, all teams are Lithuanian. They are play Lithuanian songs and you feel like in Lithuania." (Jonas)

Exuberant shows of Lithuanian national pride - complete with music, raucous crowds, drinking and partying — are now commonplace on the basketball courts of Lincolnshire. Many teams have Lithuanian names and wear green and yellow shirts, the national colors of Lithuania. The creation of such 'Diaspora spaces'-including the newly formed Lithuanian basketball league - helps to instil and maintain what has been described as a 'Diaspora consciousness': an identity rooted in the history of geographical origin that holds transgressive and creative potential in a space of a sojourn, but which is also subject to the politics of location and the interdependent actions of other groups (Brah, 1996). Similar trends have been observed among studies of British Asian cricket fans in Yorkshire, where sports venues have been shown to act as important sites for cultural and nationalistic expression for Diaspora, but which are contested by local communities (Fletcher, 2012). Similarly, data obtained in the current study suggested that a shared national habitus, reinforced through basketball, generated a sense of belonging for our participants, while at the same time serving to alienate them from the indigenous population, who apparently found many of their behaviors transgressed the tacit norms and expectations they associated with 'local' basketball 
spaces. Indeed, there was evidence to suggest that such behavior was 'racialized' by the indigenous population, and several interviews touched on the friction and occasional violence that has emerged in such contested spaces, a subject to which the paper now turns.

\section{"We Know About Basketball More Than English People..." Contested Sporting Spaces and the Quest for Significance}

Several of our participants' descriptions of their basketball experiences in the UK centered upon conflict with established indigenous group, both in terms of governance and in terms of playing style and behavior in and around games. For example, a shared sense of ownership of the symbolic success of Lithuanian basketball led many participants to question the legitimacy of existing structures of governance within the county and of the ability of local policy makers to make decisions about the sport as a whole. Conversely, participants considered themselves to be in a strong position in this regard through their Lithuanian identity, which they associated with being part of an established 'we' group within the global figuration of basketball (Elias \& Schröter, 1991). At the same time these assertions were contradicted by concomitant perceptions of participants' exclusion from power and marginalization as an outsider group at the local level. Several of Elias \& Scotson's (1994) established-outsider relationships held resonance in this case, including the tendency for members of the local established group to perceive this group of outsiders as 'law-breakers' and 'status violators' - that is, anomic, and the tendency for the local established group to judge them in terms of the 'minority of the worst' to 'other' them. For example, participants felt that their input to basketball had been largely ignored and their expertise rejected by the established group of indigenous players, coaches and policy makers. Jokubas, for example, had been a well-respected member of the league and both a coach and referee for many years, but had finally lost patience with the British system, which he believed to be exclusive:

"I introduced everything to league... they didn't want to listen, and that's why I thought we need to try to get, you know, completely different league... But problem is, I think they're more than just happy that we actually got our own league... I haven't had anything from them. Nothing at all. They just ignore me, like completely. I'm gone. No emails or phone calls. Nothing." (Jokubas)

Furthermore, feelings of exclusion were not limited to issues concerning governance. Participants described how their interpretation of the rules, playing style and etiquette also differed from local expectations. One key source of frustration related to how games were refereed exclusively by local officials. According to participants, local referees used different standards to those accepted in Lithuania, including a much lower threshold for physical assertiveness. In one case, a player had even been told by a referee that they were playing "to Lincolnshire rules, not FIBA rules" (Dominykas). This left many participants (and apparently their teammates) feeling alienated within 'their' sport because they appeared to have different behavioral expectations to the locals (Elias \& Dunning, 1986), who, according to our participants, appeared to act as though disagreements were self-evidently the Lithuanians' problem, rather than due to a failure of their own. Nojus outlined this feeling:

"The biggest issue when I started playing was refereeing. I come back always to refereeing because [the way which rules were applied] was absolutely shocking to me, like literally shocking. And it seems it's not getting any better. That's why it's very sad." (Nojus) Perceptions that match officials did not adhere to the same set of rules left many players feeling that they were singled out. In some cases, participants viewed this discrimination, or cultural racism (Burdsey, 2006b), as a threat to their identity as Lithuanians because they could not play the sport in 'our' way. This was perceived by several participants as arrogance on the part of local players. For example, Armandas explained:

"We know about basketball more than English people because most English people knows about other sports like cricket, football you know. Basketball is our life you know. English people try to think 'we're higher because we're English"” (Armandas)

The consequences of this clash of basketball habitus' regarding tolerance of acceptable behaviors caused many Lithuanian players to feel alienated from local basketball structures, competitions and teams. At the time the fieldwork was conducted, the league had just finished investigating two incidents of racism and violence that had led to the abandonment of games within the space of two weeks. Jokubas was a referee in one of the abandoned games and described his experience: "One of the players just abused me all the time. When I called a foul... he just jumped into my face and pushed me to my chest. What happened is I just pushed him away again and go to the table... then he took his bloody pants off, you know, bent down and just showed his bare backside. And what happened next you know, I pushed him with my knee. The problem is, the league haven't supported me as a referee. I had a ban until the end of the season. But that other player... what he got? Just one game ban, which in my opinion, as I said to the league, the reason why is because I'm Lithuanian" (Jokubas) Such incidents led eventually to the voluntary exclusion of many Lithuanian teams from the league, which in turn caused a full-scale split between the local basketball association and a rival, Lithuanian competition. This second competition consisted of Lithuanian teams and players, and although English players and teams were invited to join, none responded. Such a split is perhaps symptomatic of the Lithuanian Diaspora seeking to delineate and control their own spaces of sporting culture without interference from the local community and service providers. This move offers significant divergence from Elias' assertion that outsider groups internalize their inferior status as logical. Instead, their existing association of basketball as a form of resistance to oppression, as well as the expression of their expertise and national identity, led them to delineate their own basketball spaces. Still, these basketball spaces were marginalized in relation to British basketball structures and competitions, and participants expressed, with regret, their feelings that confrontation was inevitable should things be otherwise. Nojus 
described how feelings of mistrust and poor understanding between host and migrant communities were, in his opinion, increasingly ingrained:

"I think there are a lot of Lithuanians that would like separate and maybe be a little bit more closed community... I feel like that, from some English people, like feeling the pressure that we're not welcome, then same from Lithuanian players, don't want to play with English, or we better and should be separate." (Nojus)

This narrative of the initial creation of segregated leagues is in some ways consistent with Burdsey's (2006)[AUQ2] account of early postmigration racism experienced by British Asians in football and the leagues they created as 'safe-havens' from racist prejudice. The present study findings differ from this observation, however, due to the complex interweaving of established/outsider relationships between interdependent local and global levels of basketball culture. In this case, the migrant group existed at the nexus between global basketball practice, within which they considered themselves part of an established 'we' group, while simultaneously feeling part of an outsider group in relation to the administrative structures and cultural norms of basketball at the local level—as well as British culture more generally. This complex interweaving of enabling and constraining relationships made the dynamic between migrant and indigenous players particularly fractious as participants felt their expertise (which they often associated with their national identity) was being resisted or rejected, while the local population resisted the imposition of 'Lithuanian' norms and practices, which were 'racialized' and often led to confrontation. Armandas, for example, had been given a 'Lithuanian liaison' position in the league committee the previous season, but when asked if the position had helped he implied that it was little more than a token gesture:

[Has it helped?] "Not at the minute, no. Do you remember the AGM? I've been voted for committee, [but] I didn't get when there's committee meetings, anything, no info. I didn't receive any emails or any information on what committee does." (Armandas)

As is typical in established/outsider relations (Elias \& Scotson, 1994), the established group at the local level-the league committee in this case - set behavioral standards, sometimes in direct opposition to the norms of the outsider group (e.g., refereeing standards and rules). Since there were no Lithuanians on the committee outside 'token' positions, the migrant outsider group lacked the means to effectively challenge their subordination over the short-term within the existing web of relationships in the Lincolnshire basketball figuration. This was illustrated by Nojus, who described having private discussions with a committee member who "seemed like he understood and supported my thoughts" but never actually reported or represented those views at the committee. There were also a number of reported cases, like the example of Jokubas' refereeing ban, where Lithuanian members felt the league had made exceptional examples of them, as though implying violence and 'trouble' were typical of Lithuanian players. Such cases, by focusing upon the migrant group as 'lawbreakers' and focusing upon the minority of the worst, served to drive a wedge between migrant and host communities, leading to what, at the time of writing, appears to be an irreparable ethnic division in the region's basketball figuration.

\section{Conclusions}

This paper has presented interview data obtained from nine male Lithuanian migrants in the United Kingdom in relation to their experiences of participation in basketball. We have demonstrated how participation in basketball related to their migratory experiences and acculturation strategies in the face of resistance and stigmatization from the local indigenous population, which often served to 'racialize' their basketball behaviors and traditions, thereby making their group more 'visible' and subject to marginalization (Long \& Hylton, 2002; Long et al., 2014). Initially, our participants had been isolated, with poorly established bonds of association with their compatriots. Hence, for this group of migrants, basketball represented a conduit for the expression of national identity and a resource for the establishment of networks of compatriots, while the expression of Lithuanian cultural traditions on the basketball court allowed participants to feel connected to an imagined community back home. In particular, participants considered themselves part of a wider Lithuanian Diaspora in the United Kingdom, but one which was spatially dispersed. This 'we' group, which existed locally around the fulcrum of basketball competition, imagined itself globally through emphasis of the interdependence of Lithuanian and British basketball spaces. For example, while employment was often conceptualized as a 'foreign' space, during basketball matches, training and their associated social events, participants described a sense of feeling a closer connection to their homeland. By enacting practices familiar from home, for a time at least the basketball court became a Lithuanian space. The presence of all-Lithuanian teams was indicative of such a trend, as were accounts of the use of language, imagery, chants and a sense of patriotism.

Furthermore, rich descriptions of the deeply emotive nature of participants' reaffirmation of Lithuanian national identity through the embodied actions of actually playing the sport, including shooting 'for Lithuania,' underlined the centrality of basketball in terms of participant identities at the level of embodied, 'I' identities.

Moreover, Lithuanian migrants also considered themselves part of an established global group of basketball cultures due to their identification with Lithuanian national success and the preeminent position basketball held in their homeland. However, this basketball identity seemed to hold a sense that the sport was historically a focus of resistance against powerful 'others.' Hardly surprising, then, that the apparent marginalization of migrant expertise, combined with racialization and even outright hostility toward their overt displays of patriotism, resulted in such resistance from our participants. Nevertheless, it also suggests that at the local level, migrants were part of an outsider group within the local basketball figuration. Such feelings were exacerbated by poor bonds of association both between migrants and with locals through language barriers, financial exploitation in the workplace and relative lack of long-term planning during their sojourn. This made the Lithuanian group more 'visible,' marginalizing them despite their 'whiteness' (Long et al., 2014). Consequently, participants felt a sense of 
disjuncture from local basketball governance and league structures. Such a sense of exclusion also became apparent in terms of conflicting playing styles, the presence of conflicting habitus, as illustrated through application of tacit thresholds of acceptable behavior by local established groups, and the resultant conflict between migrants and locals when these thresholds were transgressed. This clash of sociocultural, national habitus has had serious consequences, with initial marginalization of Lithuanian migrants within basketball developing into the full (voluntary) self-exclusion, or accultural separation (Berry, 2005), of all-Lithuanian teams from many regional basketball league structures.

This trend appears to be indicative of a widening chasm between migrant and host populations and growing allegations of cultural racism and exclusion on both sides. Such findings represent a brief view into the subjective relationships inherent in a field which can be ignored in wider discourses of migration, which as noted above can often focus upon migrant numbers, employment figures, service utilization and the consumption of resources (Blanchflower et al., 2007; Burdsey, 2006b; Jileva, 2002; Pemberton \& Scullion, 2013). The present study, on the other hand, highlights how fields such as sport can offer unique contexts within which embodied, intercultural relationships are experienced by both hosts and migrants, either in the same space, or in some cases in voluntarily ethnically exclusive spaces such as 'All Asian Leagues' (Burdsey, 2006a). The nature of sporting competition can create contexts in which individual expressions of national and ethnic identity, which might otherwise be subsumed within wider 'racial' categories can become, literally, visible, concrete markers of playing superiority/inferiority, difference and an antagonistic 'us against them' juxtaposition of 'we' and 'they' groups. As in this case, sport became a focus and an outlet for some of the hopes, frustrations and fears that 'we' groups of migrants and indigenous communities held in relation to one another.

Nevertheless, a degree of caution is necessary in terms of the generalizability of our findings. The present study was based upon a relatively small sample of more established migrants among whose command of English was sufficient to enable their participation in an interview, and future study in which data collection is completed in Lithuanian is necessary to ascertain whether the perceptions and experiences of more recent migrants mirror those of our participants. Similarly, the study focused upon the experiences of male migrants, and further insights could be gained by focusing upon the perceptions of female migrants from the same ethnic group either as individuals or as 'migrants by association' (Stead \& Maguire, 2000) to both Lithuanian migrants, and other migrant groups from other 'A8' countries.

\section{Acknowledgments}

The authors would like to acknowledge the comments and feedback of the two anonymous reviewers, whose input is greatly appreciated.

\section{References}

Adair, D., \& Rowe, D. (2010). Beyond boundaries? 'Race', ethnicity and identity in sport. International Review for the Sociology of Sport, 45(3), 251-257. doi:10.1177/1012690210378798

Allen-Collinson, J. (2009). Sporting embodiment: sports studies and the (continuing) promise of phenomenology. Qualitative research in sport and exercise, 1(3), 279-296.

Anderson, B. (2006). Imagined communities: Reflections on the origin and spread of nationalism. London: Verso.

Anthias, F. (1998). Evaluating 'diaspora': Beyond ethnicity? Sociology, 32(3), 557-580.

Bairner, A. (2012). For a sociology of sport. Sociology of Sport Journal, 29(1), 102-117.

Bairner, A., \& Barbour, D. (2005). Where the Grass is Greener: Irish rugby union, migrant coaches and the globalisation debate. Football Studies, 8(1), 27-41.

Baur, N., \& Ernst, S. (2011). Towards a process-oriented methodology: modern social science research methods and Norbert Elias's figurational sociology. The Sociological Review, 59(s1), 117-139. doi:10.1111/j.1467-954X.2011.01981.x Berry, J.W. (2005). Acculturation: Living successfully in two cultures. International Journal of Intercultural Relations, 29(6), 697-712. doi:10.1016/j.ijintrel.2005.07.013

Blanchflower, D.G., Saleheen, J., \& Shadforth, C. (2007). The impact of the recent migration from Eastern Europe on the UK economy. IZA Discussion Papers, No. 2615, Retrieved from http://nbn-resolving.de/urn:nbn:de:101:1-2008042269 website Brah, A. (1996). Cartographies of diaspora: contesting identities. London: Routledge.

Bryman, A., \& Teevan, J.J. (2004). (Vol. 2. Social research methods. Oxford: Oxford university press.

Bude, H., \& Dürrschmidt, J. (2010). What's wrong with globalization?: Contra 'flow speak'-towards an existential turn in the theory of globalization. European Journal of Social Theory, 13(4), 481-500. doi:10.1177/1368431010382761

Burdsey, D. (2004). 'One of the lads'? Dual ethnicity and assimilated ethnicities in the careers of British Asian professional footballers. Ethnic and Racial Studies, 27(5), 757-779. doi:10.1080/0141987042000246336

Burdsey, D. (2006a). (Vol. 10. British Asians and football: Culture, identity, exclusion. London: Routledge.

Burdsey, D. (2006b). 'If I ever play football, Dad, can I play for England or India? 'British Asians, sport and diasporic national identities. Sociology, 40(1), 11-28. doi:10.1177/0038038506058435

Burdsey, D. (2009). Forgotten fields? Centralizing the experiences of minority ethnic men's football clubs in England. Soccer \& Society, 10(6), 704-721. doi:10.1080/14660970903239925

Carter, T.F. (2011a). In foreign fields: the politics and experiences of transnational sport migration. London: Pluto Press. 
Carter, T.F. (2011b). Re-placing sport migrants: Moving beyond the institutional structures informing international sport migration. International Review for the Sociology of Sport, 48(1), 66-82. doi:10.1177/1012690211429211

Cingiene, V., \& Laskiene, S. (2004). A revitalized dream: Basketball and national identity in Lithuania. The International Journal of the History of Sport, 21(5), 762-779. doi:10.1080/0952336042000262042

Cohen, R. (2008). Global diasporas: An introduction. London: Routledge.

Cook, J., Dwyer, P., \& Waite, L. (2011). The experiences of accession 8 migrants in England: motivations, work and agency. International Migration (Geneva, Switzerland), 49(2), 54-79. doi:10.1111/j.1468-2435.2009.00595.x

Demireva, N. (2011). New migrants in the UK: employment patterns and occupational attainment. Journal of Ethnic and Migration Studies, 37(4), 637-655. doi:10.1080/1369183X.2011.545308

Dicken, P. (2007). Global shift: Mapping the changing contours of the world economy. London: Paul Chapman Publishing. Dunning, E. (1999). Sport matters: Sociological studies of sport, violence, and civilization. London: Taylor \& Francis.

Dunning, E. (2005). 10 Figurational Sociology and the Sociology of Sport: Some Concluding Remarks. Taking public universities seriously, 221.

Eade, J., \& Garbin, D. (2007). Reinterpreting the relationship between centre and periphery: Pilgrimage and sacred spatialisation among Polish and Congolese communities in Britain. Mobilities, 2(3), 413-424.

doi:10.1080/17450100701597384

Elias, N. (1978). What is sociology? New York: Columbia University Press.

Elias, N. (1982). The civilizing process. New York: Pantheon.

Elias, N., \& Dunning, E. (1986). Quest for excitement: sport and leisure in the civilizing process. Oxford, New York: Basil

Blackwell.

Elias, N., Dunning, E., Goudsblom, J., \& Mennell, S. (2000). The civilizing process: sociogenetic and psychogenetic investigations. London: Wiley-Blackwell.

Elias, N., \& Jephcott, E. (1983). The court society. Pantheon Books New York.

Elias, N., \& Schröter, M. (1991). The society of individuals. New York: Continuum International Publishing Group.

Elias, N. Schroter, M. and Jephcott, E., 1987. Involvement and detachment. Oxford: Basil Blackwell.

Elias, N., \& Scotson, J.L. (1994). (Vol. 32. The established and the outsiders: A sociological enquiry into community problems. London: Sage Publications Ltd.

Evans, A., \& Stead, D. (2014). "It's a long way to the Super League": the lived experiences of southern hemisphere professional rugby league migrants in the United Kingdom. International Review for the Sociology of Sport, 49(6), 707-727. doi:10.1177/1012690212464700

Evans, A.B. (2014). Contesting far flung fields: Sociological studies of migration and acculturation through sport. In J. Merton (Ed.), Acculturation: Psychology, Processes and Global Perspectives (pp. 67-86). New York: NOVA Science Publishers.

Fletcher, T. (2012). 'Who do “they” cheer for?' Cricket, diaspora, hybridity and divided loyalties amongst British Asians. International Review for the Sociology of Sport, 47(5), 612-631. doi:10.1177/1012690211416556

Fox, J.E., Moroşanu, L., \& Szilassy, E. (2012). The racialization of the new European migration to the UK. Sociology, 46(6), 680-695. doi:10.1177/0038038511425558

Garner, S. (2006). The uses of whiteness: what sociologists working on Europe can draw from US research on whiteness. Sociology, 40(2), 257-275. doi:10.1177/0038038506062032

Gillingham, E. (2010). Understanding A8 migration to the UK since accession. London: Office for National Statistics. Giulianotti, R., \& Robertson, R. (2007). Sport and globalization: transnational dimensions. Global Networks, 7(2), 107112. doi:10.1111/j.1471-0374.2007.00159.x

Green, A.E., Owen, D., Jones, P., Owen, C., \& Francis, J. (2007). The economic impact of migrant workers in the West Midlands. Birmingham: Learning and Skills Council West Midlands Region.

Ha, J-P. (2012). The role of acculturation and ethnic identity in understanding Asians' sport consumption behavior in the United States. Louisville: University of Louisville.

Hall, S. (1990). Cultural identity and diaspora. In J. Rutherford (Ed.), Community, Culture, Difference. London: Lawrence and Wishant.

Harrolle, M.G., \& Trail, G.T. (2007). Ethnic identification, acculturation and sports identification of Latinos in the United States. International Journal of Sports Marketing \& Sponsorship, 8(3), 234-253.

Hoelscher, S., \& Alderman, D.H. (2004). Memory and place: geographies of a critical relationship. Social \& Cultural Geography, 5(3), 347-355. doi:10.1080/1464936042000252769

Hosper, K., Nierkens, V., van Valkengoed, I., \& Stronks, K. (2008). Motivational factors mediating the association between acculturation and participation in sport among young Turkish and Moroccan women in the Netherlands. Preventive Medicine, 47(1), 95-100. doi:10.1016/j.ypmed.2008.02.024

Jarvie, G., \& Maguire, J.A. (1994). Sport and leisure in social thought. London: Taylor \& Francis. doi:10.4324/9780203417614 
Jileva, E. (2002). Visa and free movement of labour: the uneven imposition of the EU acquis on the accession states. Journal of Ethnic and Migration Studies, 28(4), 683-700. doi:10.1080/1369183021000032263

Kaunaite, U. (2012). The Need to Believe in a Secularised World: Practises among the Basketball Fans in Lithuania. Ethnographic Encounters, 2(1), 47-56.

Kenny, P., \& Bedford, P. (2012). Social impact of population change: A report of the task and finish group. Boston, Lincolnshire: Boston Borough Council.

King, R. (2002). Towards a new map of European migration. International Journal of Population Geography, 8(2), 89-106. doi:10.1002/ijpg.246

Klein, A.M. (1994). Trans-nationalism, labour migration and Latin American baseball. In J. Bale \& J. Maguire (Eds.), The global sports arena: athletic talent migration in an interdependent world. London: Routledge.

Lechner, F.J., \& Boli, J. (2008). The globalization reader. Oxford: Blackwell.

Long, J., \& Hylton, K. (2002). Shades of white: an examination of whiteness in sport. Leisure Studies, 21(2), 87-103.

doi:10.1080/02614360210152575

Long, J., Hylton, K., \& Spracklen, K. (2014). Whiteness, blackness and settlement: Leisure and the integration of new migrants. Journal of Ethnic and Migration Studies, 40(11), 1779-1797. doi:10.1080/1369183X.2014.893189

Lusted, J. (2009). Playing games with 'race': understanding resistance to 'race' equality initiatives in English local football governance. Soccer \& Society, 10(6), 722-739. doi:10.1080/14660970903239941

Maguire, J. (1991). Towards a sociological Theory of Sport and the Emotions: A figurational Perspective. International Review for the Sociology of Sport, 26(1), 25-35. doi:10.1177/101269029102600104

Maguire, J. (1993). Bodies, sportscultures and societies: a critical review of some theories in the sociology of the body. International Review for the Sociology of Sport, 28(1), 33-52. doi:10.1177/101269029302800103

Maguire, J.A. (2002). Sport worlds: A sociological perspective. Human Kinetics Publishers.

Maguire, J.A. (2011). 'Real politic' or 'ethically based': sport, globalization, migration and nation-state policies. Sport in Society, 14(7-8), 1040-1055. doi:10.1080/17430437.2011.603557

Massey, D. (2005). For space. London: Sage.

McCollum, D., Cook, L., Chiroro, C., Platts, A., MacLeod, F., \& Findlay, A. (2012). Spatial, sectoral and temporal trends in A8 migration to the UK 2004-2011. Evidence from the worker registration scheme ESRC Centre for Population Change Working Papers. University of Southampton: Centre for Population Change.

McGuire, B., Monks, K., \& Halsall, R. (2001). Young Asian males: social exclusion and social injustice in British professional football? Sport in Society, 4(3), 65-80.

Murphy, P., Sheard, K., \& Waddington, I. (2000). Figurational sociology and its application to sport. In Dunning, E. and Coakley, J. J. Handbook of sports studies, London: Sage.92-105.

Office of National Statistics. (2012). Methods used to revise the national population estimates for mid-2002 to mid-2010 Office for National Statisctics: Statistical Bulletin. London: Office for National Statistics.

Pemberton, S. (2008). Supporting economic migrants in the North West of England implications for economic and social policy. Public Policy and Administration, 23(1), 80-99. doi:10.1177/0952076707083287

Pemberton, S., \& Scullion, L. (2013). The Policies and Politics of Managed Migration: Exploring Mature Labour Migration from Central and Eastern Europe into the UK. Journal of Ethnic and Migration Studies, 39(3), 443-461. doi:10.1080/1369183X.2013.733863

Roediger, D.R. (1999). The wages of whiteness: Race and the making of the American working class. Verso.

Ryan, L., Sales, R., Tilki, M., \& Siara, B. (2009). Family strategies and transnational migration: recent Polish migrants in London. Journal of Ethnic and Migration Studies, 35(1), 61-77. doi:10.1080/13691830802489176

Satzewich, V. (2000). Whiteness Limited: Racialization and the Social Construction of' Peripheral Europeans. Histoire Sociale, 33(66), 271-290.

Selvaraju, U., Ablat, P., Harris, D., Coleman, I., Schauder, T., Sabonis, A., \& Mwaba, M. (2012). The Big Question: Scoring Goals How Have Sports Transformed Your World? World Policy Journal, 29(2), 3-7.

doi:10.1177/0740277512451444

Stead, D., \& Maguire, J. (2000). "Rite De Passage" or Passage to Riches? The Motivation and Objectives of Nordic/Scandinavian Players in English League Soccer. Journal of Sport and Social Issues, 24(1), 36-60.

doi:10.1177/0193723500241004

Taagepera, R. (2009). The Struggle For Baltic History. Journal of Baltic Studies, 40(4), 451-464. doi:10.1080/01629770903320114

Thing, L.F. (2001). The female warrior. International Review for the Sociology of Sport, 36(3), 275-288.

doi:10.1177/101269001036003002

Topič, M., \& Coakley, J. (2010). Complicating the relationship between sport and national identity: the case of postsocialist Slovenia. Sociology of Sport Journal, 27(4), 371-389.

Van Krieken, R. (1998). Norbert Elias. Abingdon: Psychology Press. 
Weedon, G. (2012). 'Glocal boys': Exploring experiences of acculturation amongst migrant youth footballers in Premier League academies. International Review for the Sociology of Sport, 47(2), 200-216. doi:10.1177/1012690211399221 